\title{
High-temperature materials increase efficiency of gas power plants
}

\author{
By Angela Saini \\ Feature Editor Tresa Pollock
}

$I^{n}$ the global push to adopt more sustainable fuels, change can seem frustratingly slow. Coal still leads the pack as the most popular means of producing electricity in many countries. The disheartened, however, may find some comfort in its runnerup - natural gas, a cleaner fossil fuel than coal. By switching to gas while also improving the efficiency of gas-fired plants, carbon emissions could drop significantly in the short term.

New materials are at the heart of the challenge of driving up efficiency and reducing environmental impact. The turbine is the workhorse of a power plant, and efficiencies of current coal-fired power plants may be as low as 30 percent. Combined cycle plants, which combine a gas turbine and a steam turbine and are fueled by natural gas, are now far leaner than coal technologies. Efficiencies are starting to edge past 60 percent, with each percentage point representing a \$20 million savings in fuel over the lifetime of the plant.

The problem is that increasing the size and temperature of these combined cycle machines as a way of boosting efficiency and output puts a deep toll on the turbine blades (known as "buckets" among industry insiders). "Components are much larger and serve at base load temperature much longer than those in aircraft engines," said Maxim Konter, director of Materials and Materials Processing at Alstom, in Baden, Switzerland.

A single blade in one of these industrial gas turbines can be 10 times larger and between 20 and 30 times heavier than that of an aircraft engine. The biggest blades can weigh as much as 20 kilograms. And with rotor inlet temperatures sometimes as high as ninetenths the melting point of the blade material, it has taken more than a decade of research to develop materials large and powerful enough to withstand these kinds of grueling conditions.

The first power plant to break the 60 percent efficiency barrier sits in the Welsh village of Port Talbot, in a coastal area known as Baglan Bay. When General Electric (GE) finished constructing its $9 \mathrm{H}$ turbine in 2003 at a cost of $\$ 500$ million, it was the largest gas turbine in the world. The key to its record-breaking efficiency levels lies in a gas turbine firing temperature of $1430^{\circ} \mathrm{C}$, which was more than 100 degrees higher than the previous most efficient combined cycle systems. This in turn was made possible by the materials used to make the turbine blades - the world's largest single-crystal airfoils made of nickel-based alloys, known as "superalloys," with extra heatresistance provided by special thermal coatings made of yttriastabilized zirconia.

"Nickel-based superalloys remain the material of choice," said Stephen Balsone, a consulting engineer working on gas turbine materials and processes at GE Energy. "They possess an excellent balance of engineering properties for high-temperature structural applications, including high-temperature creep and thermal fatigue resistance along with high-temperature oxidation resistance."

With up to 10 main alloying elements, Konter said that the difficulty for the materials scientist lies in striking the right balance between them to produce the best qualities. "For example, chromium is essential to provide sufficient hot corrosion resistance, but at the same time is detrimental for phase stability and strength. Rhenium (which has a melting point of $3180^{\circ} \mathrm{C}$ ) increases high-temperature strength, but is extremely expensive

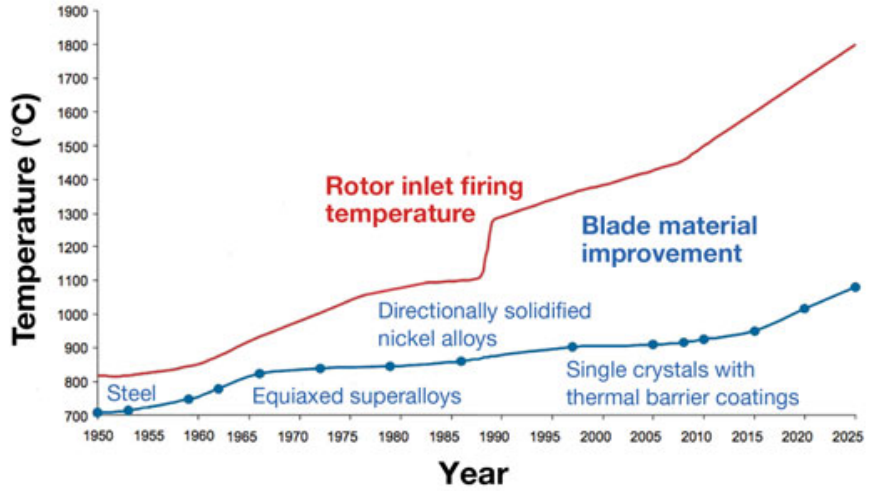

Figure 1. The benefit of materials to turbine firing temperature over time. Advanced crystal growth techniques have permitted complex cooling technologies to be employed in the interior of the blades, also contributing to efficiency. Adapted from the National Energy Technology Laboratory, US Department of Energy. 


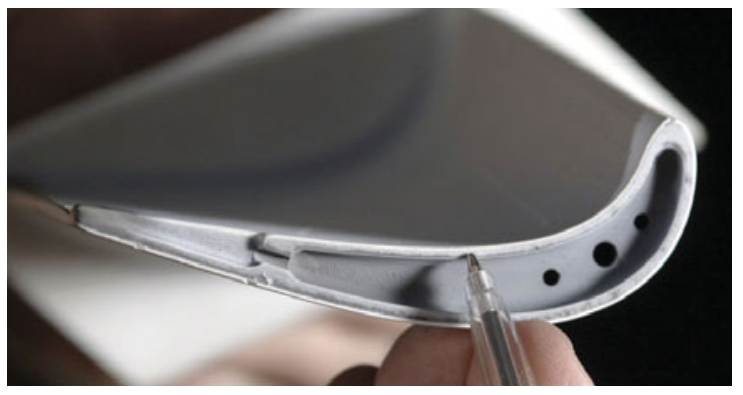

Figure 2. The 300- $\mu \mathrm{m}$-thick coating developed by Werner Stamm at Siemens to increase the service life and temperature resistance of turbine blades. Image provided by Siemens AG.

and affects the long-term stability of an alloy structure," he said. For this reason, emerging tools for modeling the properties of these multicomponent materials are very important to the development of future materials solutions.

For strength, the grain boundaries in these nickel-based superalloys need also to be parallel to the direction of the stress that is being applied or have no grain boundaries at all. The ideal structure is a single crystal. But these single crystals are susceptible to defects that form during their fabrication, including cracks, high-angle boundaries, freckling, and porosity, said Balsone. And with blades as long as $45-80 \mathrm{~cm}$, making single crystals this large and yet defect-free has been an enormous challenge.

Indeed the entire history of nickel-based superalloys for use in turbine engines can be found in the way they have been fabricated. From the 1970s onward, casting methods have shifted from producing an equiaxed microstructure (with axes of roughly the same length), to columnar grains and finally single crystals. Every improvement has brought better temperature strength, oxidation resistance, and efficiency savings (see Figure 1).

Conventionally, the alloy would be induction melted before dropping into a heated mold and withdrawn into a water-cooled vacuum chamber until it solidified (known as the Bridgman approach). But since this can lead to freckles and misoriented grains, this approach was modified to use a liquid metal coolant - a bath of $18,000 \mathrm{~kg}$ of liquid tin at $250^{\circ} \mathrm{C}$, or sometimes aluminum - instead of relying on radiation cooling in the vacuum furnace. This increases the thermal gradients while the alloy solidifies, driving up cooling rates and eliminating freckle defects.

Today, GE Energy produces some of the largest nickel-based superalloy single crystals in the world for use in seven gas turbine product lines, said Balsone. The latest, the FlexEfficiency 50 Combined Cycle Power Plant carrying the 9FB gas turbine engine, boasts an efficiency of greater than 61 percent. The first is due to enter service in 2015 at Bouchain in northern France.

Alstom has developed similar technologies. The Pembroke Combined Cycle Power Station in Wales, which is due to go operational next year, will hold the GT26 gas turbine with an efficiency of 61 percent, said Konter.

Meanwhile, ceramic thermal barrier coatings have been no less of a materials challenge than the turbine blades. The job of this protective layer on the blades is to significantly reduce the amount of heat that reaches the metal, which means it must have very low thermal conductivity. "There was a big development in this area in the early 1990s," said Willibald Fischer, the director of Gas Turbine Product Management at Siemens AG, Germany. When temperatures in gas turbines began to rise, oxidation coatings proved not to be enough - extra thermal barrier coatings were needed too. One of the problems, said Fischer, was that the nickel-based superalloy had a larger thermal expansion coefficient compared to the ceramic coating, which caused cracks. Siemens overcame this by coming up with novel electron beam physical vapor deposition approaches to apply the coating and by making the coating thinner said Fischer.

There have also been improvements to the thin adhesive layer between the blade and the ceramic coating. Werner Stamm, a materials scientist at Siemens Power Generation in Germany, helped increase the service life of turbine blades by developing a "bond" coating, which boosts the heat and corrosion resistance of the blades (see Figure 2). His invention came about by adding two percent rhenium to cobalt, nickel, chromium, aluminum, and yttrium. This bond coating forms a protective blanket of aluminum oxide at high temperatures, while the rhenium helps stop the aluminum from diffusing into the nickel-based superalloy underneath.

Without Stamm's bond coating, a turbine blade's nickel superalloy would last just 4000 hours of operation at maximum operating temperatures. With it, the blade lasts as long as 25,000 hours. It is already in use in a combined cycle power plant in Irsching, Bavaria. The plant's efficiency exceeds 60 percent.

The next goal for materials scientists and engineers working on gas turbines is to extend the lifespan of turbine components further and to lower costs. Balsone said, "There is always a trade-off between part performance, for example operating at higher temperatures, and part life. In general in the gas turbine business, improved materials mean higher temperature-capable materials. But we also want longer life and lower cost."

Fischer suggests that the ideal turbine blade could include no nickel-based superalloy at all. "If you could end up with the whole part being made of some sort of ceramic, like the coating material is made from, that would be better." But this will require many more years of research and development.

In the meantime, materials engineers can at least bask in the success of having pushed the boundaries of what gas-fired power plants can do. Natural gas may not be the most fashionable of modern energy sources, but these incremental efficiency savings have made it a far kinder fuel to the environment than it once was. The 2005 Annual Energy Review said that 51 percent of electricity in the United States came from coal, while 16 percent came from natural gas. If 1400 large coal-fired plants were replaced with gas-fired plants, this would represent as much of a saving in carbon emissions as stopping all deforestation, or cutting electricity use in homes, offices, and stores by 25 percent. And as efficiencies crawl higher, the savings become even greater. 